\title{
Crowned Dens Syndrome: Calcium Pyrophosphate Deposition Disease Masquerading as Osteomyelitis
}

ALEXANDER HECK, MS4, University of Missouri School of Medicine; NATHANIAL NOLAN, MD, MPH, Department of Medicine, University of Missouri; CHRISTIAN ROJAS-MORENO, MD, Department of Medicine, Divisions of Infectious Diseases and Hospital Medicine, University of Missouri, Columbia, Missouri, USA. Address correspondence to A. Heck, 679 Carman Meadows Drive, Ballwin, Missouri 63021, USA. E-mail: heckalexj@gmail.com. This case report was reviewed and approved by the institution's Research Ethics Board, MU Institutional Review Board through Mizzou Research eCompliance, with Project Number 2209072, and Review Number 228595. Written consent was obtained from the patient for this report. J Rheumatol 2018;45:1422-3; doi:10.3899/jrheum.170921

Crowned dens syndrome (CDS) is a clinical and radiological entity consisting of acute neck pain, accompanied by specific radiographic findings of calcifications from calcium pyrophosphate dihydrate crystals superior to and surrounding the dens of the axis, resulting in a "crown-like" appearance on coronal views ${ }^{1}$.

A 76-year-old female presented from an outside hospital for concern of osteomyelitis, with persistent neck pain following treatment for Escherichia coli sepsis. She had mild tenderness to palpation but intense pain with movement, and the pain severely limited her range of motion.

Laboratory results were remarkable for an erythrocyte sedimentation rate of $39 \mathrm{~mm} / \mathrm{h}$ and C-reactive protein of 20.4 $\mathrm{mg} / \mathrm{dl}$. Reread of the outside magnetic resonance imaging suggested edema along the odontoid process with a small

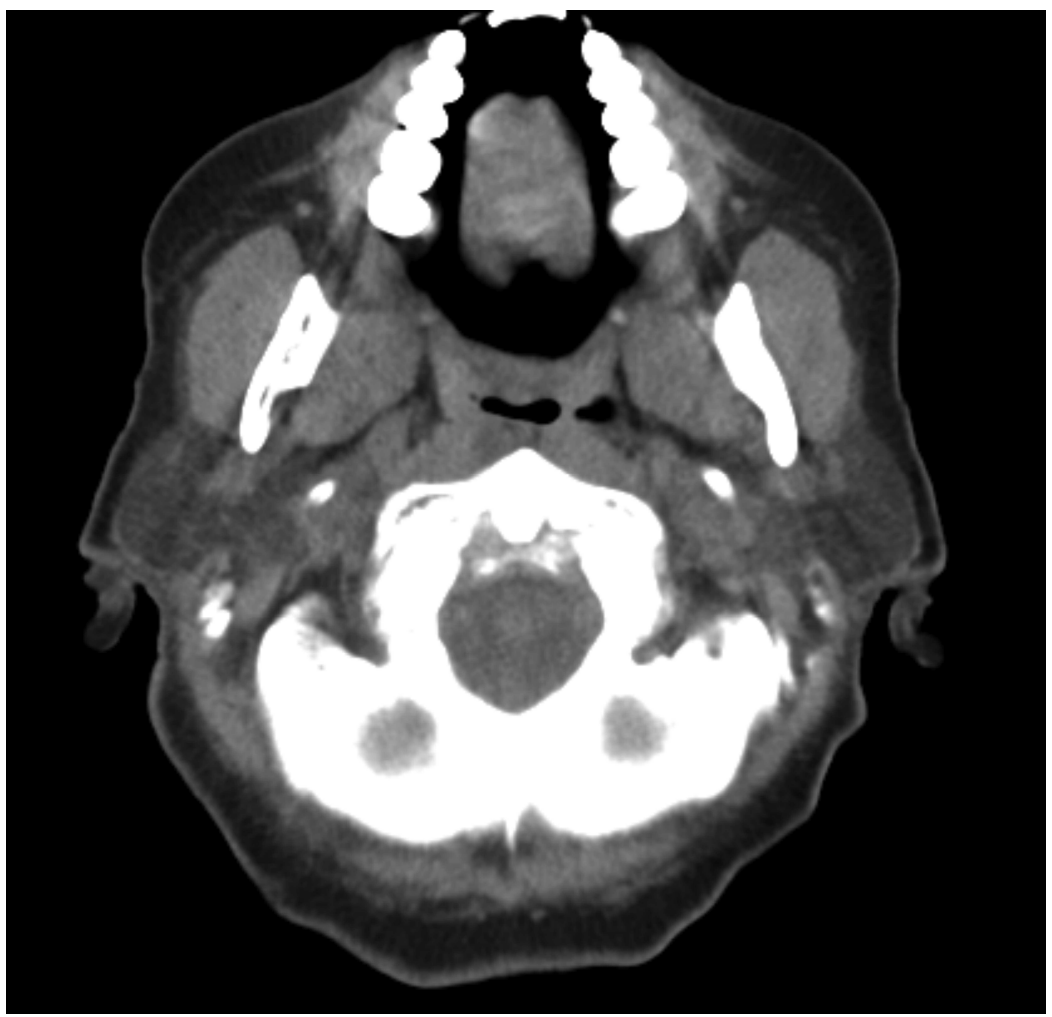

fluid collection. Computed tomography (CT)-guided aspiration of the fluid revealed positively birefringent rhomboid crystals. CT images demonstrated calcification around the odontoid process of C2 (Figure 1 and Figure 2). A diagnosis of CDS was made. The patient markedly improved with colchicine and naproxen. Further history revealed episodes of intermittent joint pain, self-treated with nonsteroidal antirheumatic drugs (NSAID). A wrist radiograph confirmed peripheral calcium pyrophosphate deposition disease (CPPD).

In CDS, routine laboratory findings are nonspecific, yet inflammatory markers are often elevated ${ }^{2}$. The differential diagnosis includes giant cell arteritis, osteomyelitis, meningitis, and retropharyngeal abscess ${ }^{3}$. A CT scan revealing calcification around the odontoid process accompanied by

Figure 1. An axial CT image of our patient's cervical spine, illustrating the "crowning" of the dens. This density represents calcium pyrophosphate dihydrate deposition in the ligaments surrounding the odontoid process of $\mathrm{C} 2$. CT: computed tomography. 


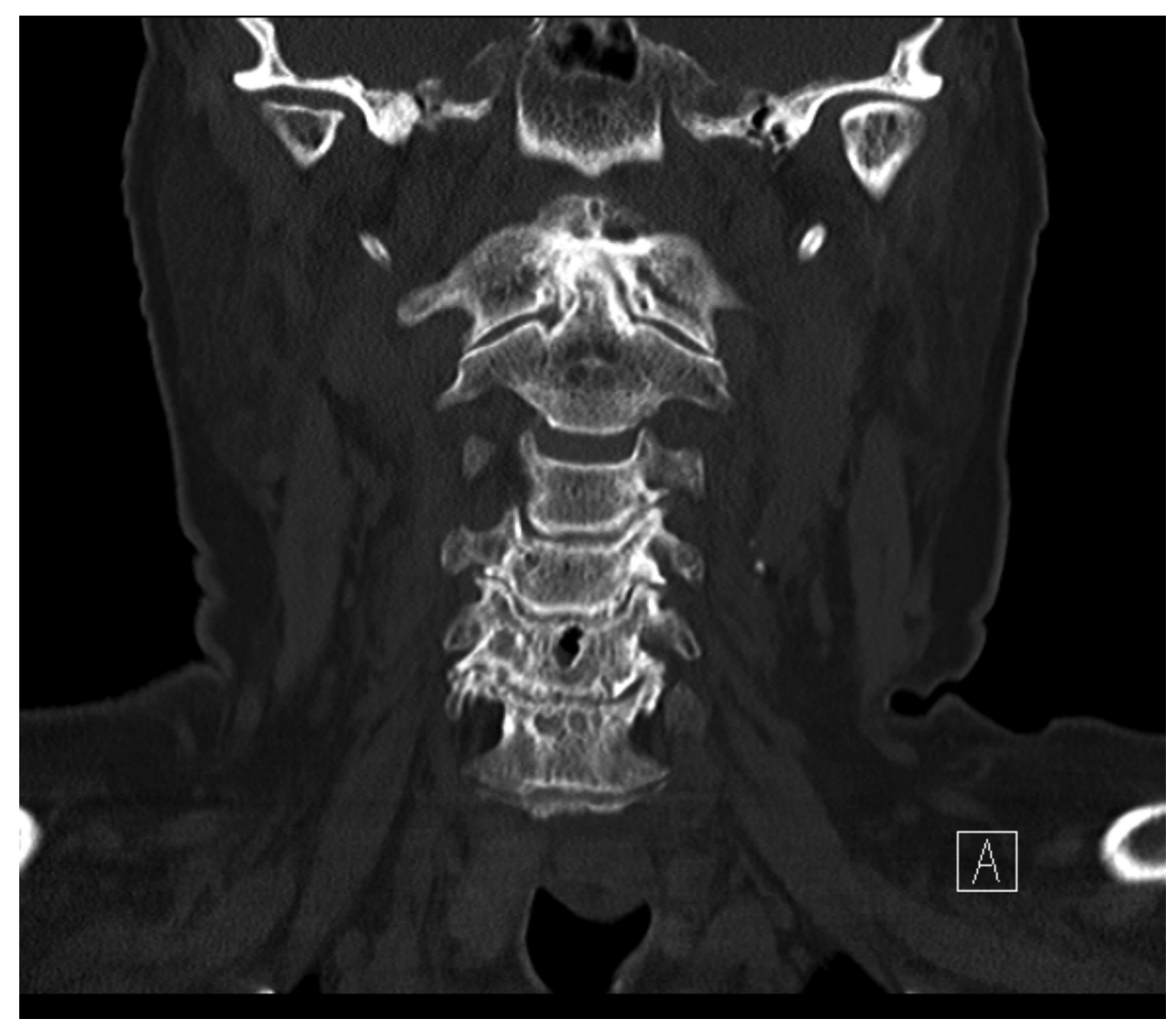

Figure 2. A coronal CT image of our patient's cervical spine, which illustrates radio-dense opacities blurring the space between the dens (odontoid process of $\mathrm{C} 2$ ) and surrounding articular facet of the axis (C1). CT: computed tomography.

acute neck pain is diagnostic; however, aspiration is acceptable, as in this case ${ }^{4}$. Plain radiographs are nonspecific in the cervical spine but can confirm peripheral CPPD. Patients respond well to NSAID, colchicine, and corticosteroids, suggesting CDS is often treated symptomatically without formal diagnosis 5 .

\section{REFERENCES}

1. Bouvet JP, le Parc JM, Michalski B, Benlahrache C, Auquier L. Acute neck pain due to calcifications surrounding the odontoid process: the crowned dens syndrome. Arthritis Rheum 1985;28:1417-20.
2. Takahashi T, Tamura M, Takasu T, Kamei S. Clinical and quantitative analysis of patients with crowned dens syndrome. J Neurol Sci 2017;376:52-9.

3. Aouba A, Vuillemin-Bodaghi V, Mutschler C, De Bandt M. Crowned dens syndrome misdiagnosed as polymyalgia rheumatica, giant cell arteritis, meningitis or spondylitis: an analysis of eight cases. Rheumatology 2004;43:1508-12.

4. Lee GS, Kim RS, Park HK, Chang JC. Crowned dens syndrome: a case report and review of the literature. Korean J Spine 2014; 11:15-7.

5. Tajima K, Ueda T, Ueno K, Shimizu C, Yoshizawa J, Hori S. Crowned dens syndrome: reports of six cases and review of the literature. Acute Med Surg 2016;3:155-8. 